\title{
Round and round it goes
}

This month, we celebrate the discovery of electromagnetic rotation, the principle behind the electric motor.

T oday we hardly notice the electricity that powers our devices, lights our homes and drives our public transport systems. But 200 years ago - half a century before the first electric street lights were installed in Paris - electricity mainly moved the minds of scientists. One of the people exploring this phenomenon was Michael Faraday, whose name is now indelibly linked to electromagnetism.

On 3 September 1821, Faraday was busy in his laboratory (https://go.nature. com/3k10FjP) in the basement of the Royal Institution studying the effects of electromagnetism, which had only been discovered a year before. As he noted in his lab book (https://go.nature. com/3gdiVW6), he immersed a permanent magnetic needle in the centre of a container filled with mercury, over which he placed a hanging stiff wire. When the apparatus was connected to a battery, the wire started to rotate around the magnet. Faraday had transformed electrical energy into mechanical motion. He had discovered the principle of electromagnetic rotation.
This simple electric motor was driven by the Lorentz force experienced by a charge moving through a magnetic field, which generated a torque that caused the wire to rotate. Although Faraday discovered a host of electromagnetic phenomena and devices, his first motor did not find direct applications. However, it inspired further works that ultimately resulted in the realization of electric motors.

It didn't take long until they found their way into technological applications. Electric motors were - and still are - used to turn wheels, propel boats and move locomotives. However, their adoption was rivalled by the internal combustion engine, which transforms chemical energy into mechanical work and is still the most common car engine today.

But combustion engines burn fossil fuels and the resulting pollution has tarnished their image as the driver of modern society. In the face of inevitable climate change, the electric motor has made a comeback in transportation and electric cars have become a common sight.

Indeed, electric motors are typically more efficient than internal combustion engines and they don't run directly on fossil fuel. But the overall carbon footprint of an electric car can still be significant. One factor is, of course, the generation of the electricity they run on. If the motor is driven by electricity generated from renewable sources they are relatively clean, but that is not always the case.

Perhaps a more important challenge faced by electric-car manufacturers concerns batteries. Their production is far from environmentally friendly, emitting greenhouse gases and consuming precious metals and rare-earth elements (Nature 596, 336-339; 2021). To build a sustainable future, we are in dire need of more efficient batteries made from resource-efficient materials, and battery research is going strong. Thus, Faraday's motor is driving another generation of scientists and engineers 200 years after its invention, and maybe their work will have an equally long-term effect.

Published online: 8 September 2021 https://doi.org/10.1038/s41567-021-01361-6

\section{A night for science}

The European Researchers' Night provides a platform for scientists to engage with the public.

S cientists are adept at sharing their discoveries with their peers, but communicating science with the public is often not prioritized - and sometimes unfairly so. In these times of fake news and alternative facts, it is more important than ever for scientists to act as explainers and advocates of the scientific method. The European Commission has long appreciated the value of communicating science to the general public. And by making funds available for its annual European Researchers' Night (ERN), it has taken the open-day concept to a pan-

European level (https://go.nature. com/3CWM4hP).

The ERN traditionally happens on the last Friday in September. Successful applicants use funding to offer activities in the form of science shows and exhibitions
- the target audience being the public at large, with a focus on children and young people and, particularly, those who are not immediately exposed to scientific research. This year, proposals had to include an explanation of how possible pandemic-related restrictions could be mitigated. A total of 48 projects were successful in 29 European Union member states and associated countries, so the chances are that, if you're in Europe, there is an event happening near you (https://go.nature.com/2W8AXSk).

The Night is not just about offering people a fun afternoon (or evening) out. Proposals were assessed for how they help increase societal awareness of the importance of research and innovation. They also must seek to promote excellence in research across Europe and beyond, and attract the interest of young people in a career in scientific research. In addition, the European Commission requires events to promote diversity and inclusion in research and innovation, and to connect with its European Green Deal initiative (https://go.nature.com/3ssZ0at) - a commitment to make Europe climate-neutral by 2050 .

This year's ERN is the last funded by Horizon 2020, but it will be reincarnated in the Horizon Europe funding cycle set to last until 2027. So if you happen to be in Europe, go out and get inspired on 24th September. And perhaps even consider becoming an organizer in 2022 (https://go.nature. $\mathrm{com} / 3 \mathrm{k} 3 \mathrm{qkbz})$.

Published online: 8 September 2021 https://doi.org/10.1038/s41567-021-01362-5 